\title{
Research on Fracture and Energy Evolution of Rock Containing Natural Fractures under Cyclic Loading Condition
}

\author{
Xueliang Li $\mathbb{D}^{1,2}$ Yu Wang $\mathbb{D}^{3},{ }^{3}$ Shuo $\mathrm{Xu}^{3}$ Haonan Yang, ${ }^{3}$ and $\mathrm{Bo} \mathrm{Li}^{3}$ \\ ${ }^{1}$ China Coal Science and Technology Ecological Environment Technology Co., Ltd., Beijing 100013, China \\ ${ }^{2}$ China Coal Research Institute, Beijing 100013, China \\ ${ }^{3}$ University of Science \& Technology Beijing, Beijing 100083, China
}

Correspondence should be addressed to Yu Wang; wyzhou@ustb.edu.cn

Received 21 March 2021; Accepted 30 April 2021; Published 20 May 2021

Academic Editor: Feng Xiong

Copyright (c) 2021 Xueliang Li et al. This is an open access article distributed under the Creative Commons Attribution License, which permits unrestricted use, distribution, and reproduction in any medium, provided the original work is properly cited.

For rock engineering in cold regions, the naturally fractured rock is susceptible to repeated freeze-thaw (F-T) weathering, coupled fatigue conditions of freeze-thaw (F-T), and stress disturbance act on rock mass, which can lead to the instability of rock engineering and even occurrence of geological hazards. Knowledge of how natural fracture affects the overall fracture evolution of freeze-thawed rock is crucial to rock mass stability. Laboratory multilevel cyclic loading tests are conducted to reveal the fatigue behavior and energy evolution for naturally fractured marble, as well as the influence of natural fracture volume on fracture evolution. The test results show that the preexisting natural fracture impacts fatigue strength, lifetime, and energy dissipation. The dissipated energy is correlated to all kinds of natural fracture (i.e., opening-mode, closing-mode, and fillingmode), and it decreases with the increase of the total natural fracture volume. The dissipated energy presents a first slow and then faster pattern as the cycle number grows. Compared with newly formed cracks, the proportion of energy consumed by stimulating natural cracks is smaller.

\section{Introduction}

Rock mass often consists of different types of discontinuous structures such as joints and faults; the preexisting fractures significantly impact rock geomechanical behaviors [1-3]. The naturally fracture rock is susceptible to irreversible damage or even instability due to stress disturbance resulting from earthquake, blasting, excavation, drilling, rock cutting, hydrofracturing, etc. [4-6]. Thus, it is crucial to reveal the geomechanical behaviors and damage evolution of naturally fractured rock under stress disturbance condition to predict the long-term stability of rock in mining, civil, tunneling, and energy field, etc.

Generally, the stress disturbance is equivalent to cyclic loading, and the loading and unloading experiments have been widely performed on various kinds of rocks. Some of the main factors that influence rock fatigue mechanical properties have been investigated including the upper stress, loading frequency, dynamic stress amplitude, and loading waveform type. [7-12]. Because of the complexity of the applied loading path, the rock deformation and failure process involves complex mechanical behaviors. The macroscopic stress-strain curve is widely used to describe rock failure process; however, even though for rock having similar stress-strain curves, the internal damage evolution process may be totally different [13]. In view of this, many studies on rock damage evolution are focused on energy exchanges during rock failure [14-16]. As energy conversion is an irreversible thermodynamic process, energy dissipation and release drive rock damage evolution to the final failure. Energy contains lots of information about rock fracture parameters, such as stress, strain, and modulus of elasticity. The monitoring power is nondestructive and does not require terminating the test. Energy is a scalar quantity that can be accumulated and calculated, which can accurately reflect the whole physical process of rock fatigue failure. Therefore, there are considerable advantages to select energy as damage variable compared to other parameters. After a detailed literature review, it is obvious that plenty of studies have been performed for rock under static loading conditions, including uniaxial 
compression $[17,18]$, triaxial compression $[19,20]$, tensile stress [21, 22], dynamic compression [23, 24], and unloading process $[25,26]$; energy conversion during rock deformation has been well investigated. However, for rock subjected to cyclic loads, rock damage evolution using the energy method is relatively few. Li et al. [27] considered rock initial damage and established an energy-based model with the dissipated energy for sandstone under constant stress amplitude loads. Wang et al. [28] carried out a cyclic stress unloading experiment, which revealed the anisotropic deformation and energy evolution characteristics of interbedded marble. Zhang et al. conducted a multifrequency cyclic loading test on the energy dissipation characteristics of coal and studied the influence of frequency on the energy dissipation rate. Wang et al. also proposed an energy dissipation model that is different from the traditional damage model. Generally, some mechanical parameters, such as strain, stress, and elastic modulus are used to establish a fatigue damage constitutive equation. The drawback of this method is that the stress and strain information is relatively simple and not well reflects the internal damage of rock. $\mathrm{Pu}$ et al. [29] investigated the creep property of rock under cyclic loading and a viscoelastoplastic constitutive model was established by introducing the energy method; the reliability of the model was verified using the experimental data. Yang et al. [30] conducted multilevel cyclic loading tests on cylindrical coal samples to reveal the peak stress on the coal fatigue strength and energy dissipation. Liu et al. [31] conducted cyclic loading testing on jointed rock-like material, and the influences of dynamic frequency on energy dissipation and release were discussed. Bagde and Petroš [32] revealed the fatigue and dynamic energy evolution characteristics of rock under cyclic loads; the influence of loading frequency on energy conversion was clarified. For the studies above, cyclic/fatigue experiments were carried out on intact or preflawed rock samples; stress disturbance on the geomechanical properties of naturally fractured rock is not common. In addition, the influence of the preexisting natural fractures on energy dissipation is not well understood.

The purpose of this work is to examine the energy evolution characteristics in marble containing different natural fractures and to propose a damage model under fatigue loading for rock under cyclic loads. The influence of initial natural fracture volume on the energy conversion is deeply investigated in this work.

\section{Test Methods}

2.1. Test Rock Material Description. Marble blocks were obtained from an open-pit slope western of China in a high cold region. Due to open-pit mining activities, the rock slope is subjected to complex stress disturbance loading, such as excavation, blasting vibration, and tramcar vehicle loading. After observing the fresh rock section by blasting excavation, plenty of opening-mode fractures, closing-mode fractures, and pyrite filling-mode fractures were distributed inside the rock mass. All the natural fractures show a dominant orientation, and their dip angle is about $38^{\circ}$. Figure 1 shows the typical marble samples containing natural fractures used in this work $((\mathrm{a}-\mathrm{d})$ observation of the marble samples NFM3,
NFM4, NFM1, and NFM13 from four directions of anterior, left, posterior, and right). Typical marble samples are shown in Figure 1; obvious natural fracture can be observed, and the statistic results of the natural fracture volume are listed in Table 1.

2.2. Research Idea. The testing devices used in this work include a GCTS RTR 2000 rock mechanics testing machine and a micro-CT machine. Multilevel cyclic loading experiments were carried out at the rock mechanics testing apparatus. The detailed descriptions of the testing device can be found from the studies of Wang et al. [7, 15]. During the fatigue loading stage, the dynamic loading frequency is set to be $0.5 \mathrm{~Hz}$, and the incremental stress amplitude is $5 \mathrm{MPa}$; for rock subjected to 50 cycles, the stress amplitude increases at the next loading level until rock failure. From the studies of Zhang et al. [21], Solecki and Conant [33], and Wang et al. [28], the total energy, elastic energy, and the dissipated energy can be obtained as below:

$$
\begin{aligned}
& u=\int_{\varepsilon_{1}}^{\varepsilon_{\max }} \sigma d \varepsilon=\sum_{i=1}^{n} \frac{1}{2}\left(\sigma_{i}+\sigma_{i+1}\right)\left(\varepsilon_{i+1}-\varepsilon_{i}\right), \\
& u_{e}=\int_{\varepsilon_{1}}^{\varepsilon_{\max }} \sigma d \varepsilon=\sum_{i=1}^{n} \frac{1}{2}\left(\sigma_{i}+\sigma_{i+1}\right)\left(\varepsilon_{i+1}^{e}-\varepsilon_{i}^{e}\right), \\
& u_{d}=u-u_{e}=\int_{\varepsilon_{1}}^{\varepsilon_{\max }} \sigma d \varepsilon-\int_{\varepsilon_{2}}^{\varepsilon_{\max }} \sigma d \varepsilon .
\end{aligned}
$$

If we obtain the energy expression, the damage can be calculated from the dissipated energy of each cycle:

$$
D=\frac{\sum_{i=1}^{N_{i}} U_{i}^{d}}{\sum_{i=1}^{N_{f}} U_{i}^{d}} .
$$

\section{Results and Analysis}

3.1. Represented Cyclic Stress-Strain Curves. Due to the preexisting of natural fractures inside marble samples, the cyclic stress-strain behaviors present an obvious difference, as plotted in Figure 2. Typical marble samples containing natural fractures are used in this work. It was observed that the marble samples of NFM3, NFM4, NFM1, and NFM13 came from four directions of anterior, left, posterior and right; the fatigue lifetime of the tested sample is $822,550,385$, and 338 cycles for a typical sample with initial fracture volume ratio of $0.68 \%, 1.03 \%, 1.53 \%$, and $2.27 \%$, respectively. Affected by initial natural fractures, the stress-strain curves also show different patterns. For marble sample of NFM13 with the smallest natural fracture volume, the scale of the hysteresis loop is less than the other three samples. Although rock failure occurs at the highest stress level, the dissipated energy is not so large than the other samples. The appearance of the hysteresis loop indicates the energy dissipation of the crack, and the dissipated energy is used to drive the crack growth. Due to the existence of natural cracks, the stress-strain curve also shows different laws. For the marble sample of NFM 13 with the smallest natural fracture volume, the scale of the 


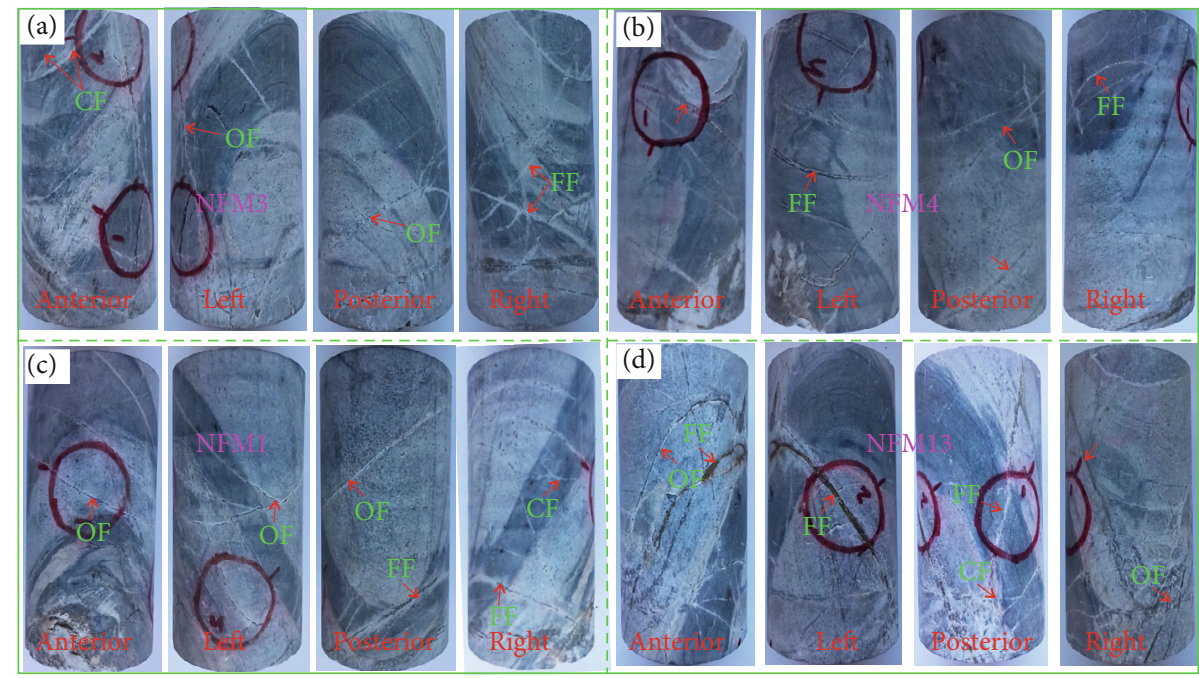

FIGURE 1: Typical marble samples containing natural fractures used in this work ((a-d) observation of the marble samples NFM3, NFM4, NFM1, and NFM13 from four directions of anterior, left, posterior, and right).

TABLE 1: Statistical analysis of the natural fracture volume within the marble samples.

\begin{tabular}{lcccc}
\hline $\begin{array}{l}\text { Sample } \\
\text { ID }\end{array}$ & $\begin{array}{c}\text { Total natural fracture } \\
\text { volume ratio } \\
R_{\mathrm{V}}(\%)\end{array}$ & $\begin{array}{c}\text { Opening-mode fractures and sealed } \\
\text { with calcite } \\
R_{\mathrm{VO}}(\%)\end{array}$ & $\begin{array}{c}\text { Closing-mode fracture with } \\
\text { quartz vein } \\
R_{\mathrm{VC}}(\%)\end{array}$ & $\begin{array}{c}\text { Filling-mode fracture with } \\
\text { pyrite bands } \\
R_{\mathrm{VP}}(\%)\end{array}$ \\
\hline NFM3 & 2.27 & 0.51 & 1.18 & 0.58 \\
NFM4 & 1.53 & 0.81 & 0.11 & 0.61 \\
NFM1 & 1.03 & 0.62 & 0.05 & 0.36 \\
NFM13 & 0.68 & 0.09 & 0.24 & 0.35 \\
\hline
\end{tabular}

hysteresis loop is less than the other three samples. Although rock failure occurs at the highest stress level, the dissipated energy is not so large than the other samples.

\subsection{Changes of Dynamic Elastic Parameters. In this section,} two dynamic elastic parameters of secant modulus (Es) and Poisson's ratio $(v)$ are analyzed for marble samples at various cyclic levels. Within a cycle level, $v$ increases with the increase in the number of cycles, and the rate of increase increases with the increase in the cycle level. The rapid increase in Poisson's ratio indicates a sharp increase in rock lateral deformation, which leads to an increase in volume deformation. For natural fractured marble samples, this result shows that the shear sliding phenomenon of natural fractures is more obvious under high cycle levels. In addition, Es decreases within a cyclic level. The decrement of Es indicates the degradation of rock stiffness, and the cyclic loads results in the damage accumulation inside rock samples. The result in Figure 3 also indicates that Es is impacted by the preexisting natural fracture volume. Es presents a decreasing trend with increasing natural fracture volume; it is shown that Es is the maximum for the sample NFM13 and it is the minimum for NFM3. The evolution of Poisson's ratio with cyclic level is plotted in Figure 4. Within a cyclic level, $v$ increases with the cycle number and the increasing rate become larger with increasing cyclic level. A fast increment of Poisson's ratio indicates an abrupt increase of rock lateral deformation, and this would result in the increase of volumetric deformation. For the natural fractured marble samples, this result implies that the shear-sliding of natural fracture become obvious at high cyclic level.

3.3. Energy Conversion during Fatigue Experiments. The macroscopic stress-strain curves display plastic deformation of marble samples. Plastic deformation resulted from irreversible deformation enhancing rock accumulative damage. For rock containing preexisting natural fracture, the damage can be attributed to the closure and sliding of natural fractures, the compaction of rock matrix, and the formation of new cracks. It is widely accepted that rock damage can be attributed to the energy dissipation during the whole deformation process [12-14]. Based on Equations (1)-(3), the energy evolution characteristics of $U, U_{e}$, and $U_{d}$ during rock deformation is plotted in Figure 5. The results show that under monotonic loads, the overall trend of the energy curve is similar to that of rocks. In the initial cyclic loading stage, almost all input energy is converted into elastic energy, which is stored in the rock; rock damage is small, and dissipated energy consumption is small.

The total energy curve coincides with the elastic energy curve, and the dissipated energy is zero. As the number of fatigue cycles increases, the rock is damaged, closing-mode 


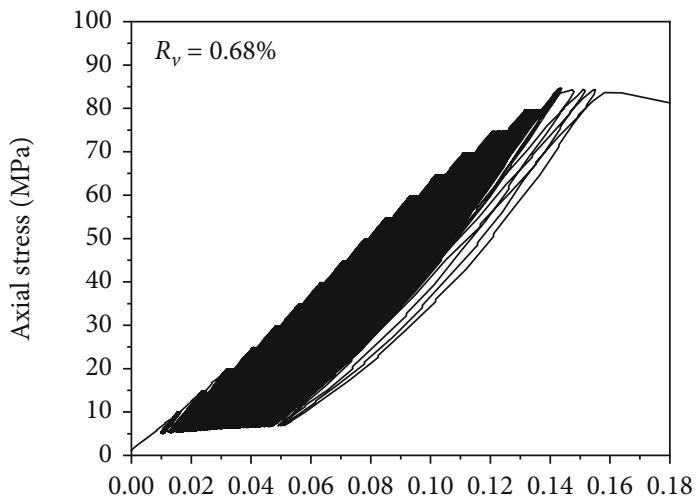

Axial strain (\%)

— Ea-Axial strain

(a)

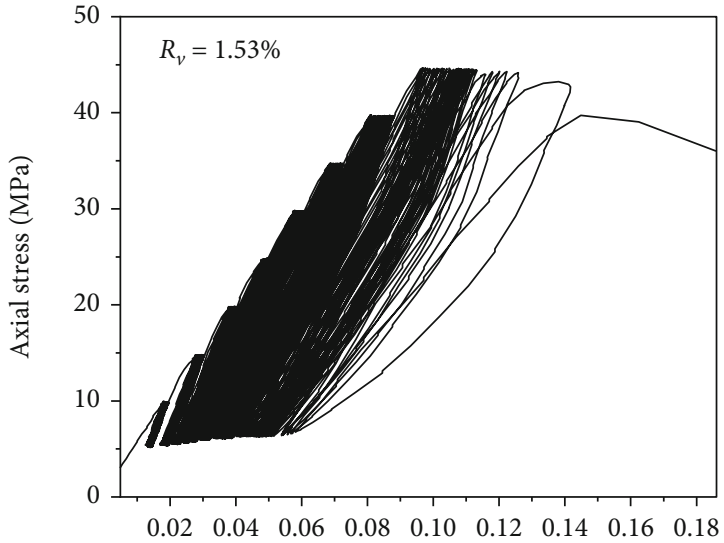

Axial strain (\%)

__ Ea-Axial strain

(c)

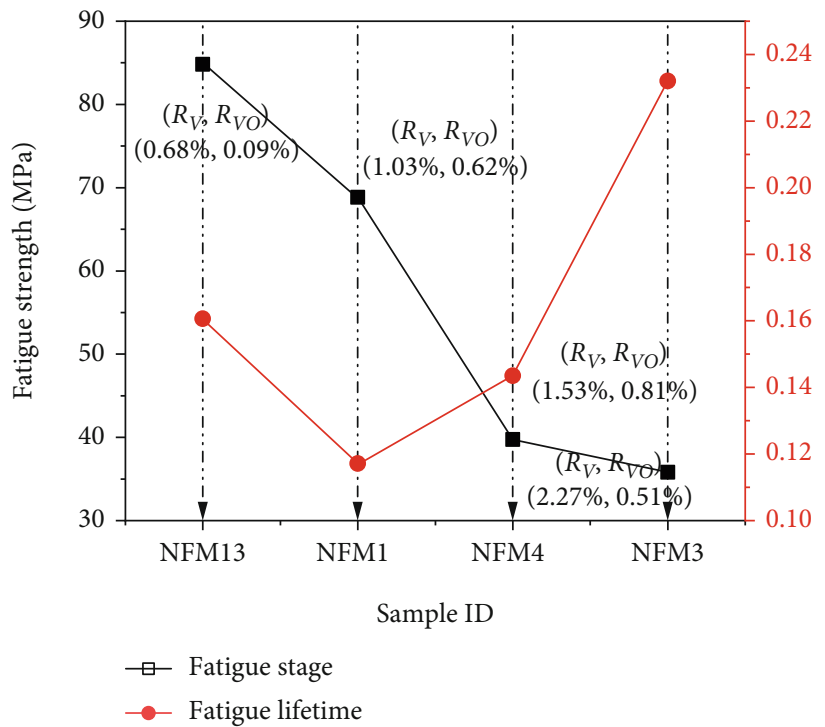

(e)

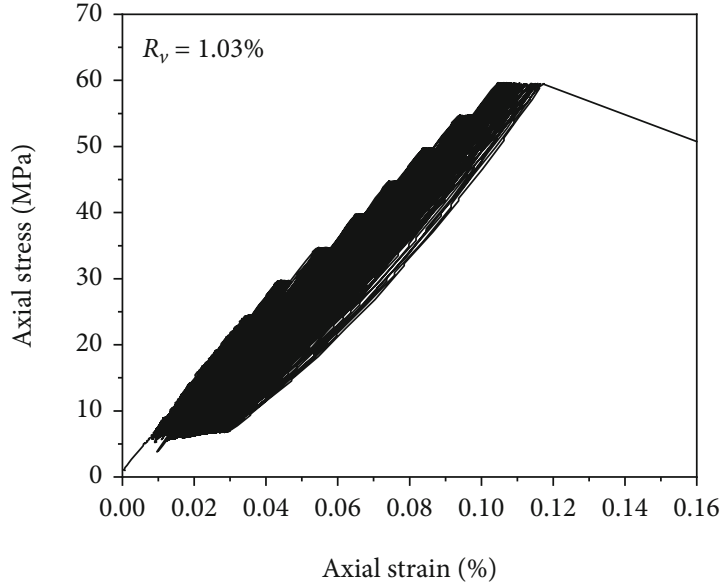

— Ea-Axial strain

(b)

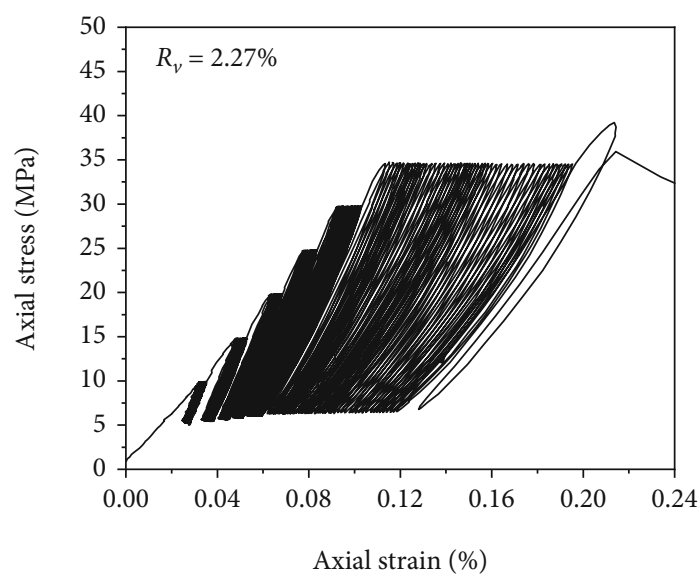

_ Ea-Axial strain

(d)

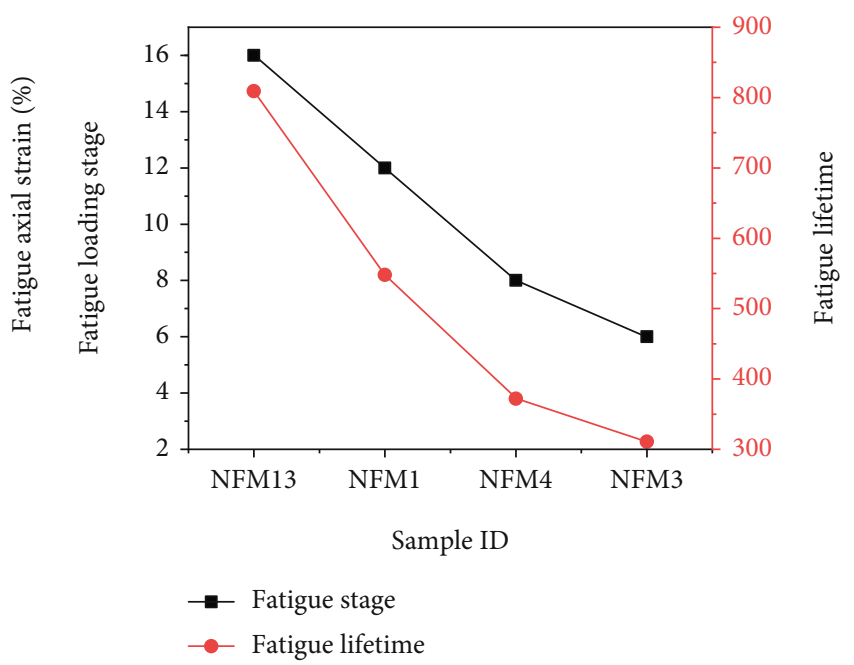

(f)

Figure 2: Represented stress-strain curves for the marble samples ( $(\mathrm{a}-\mathrm{d})$ the initial natural fracture volume ratio is $0.68 \%, 1.03 \%, 1.53 \%$, and $2.27 \%$, respectively). 


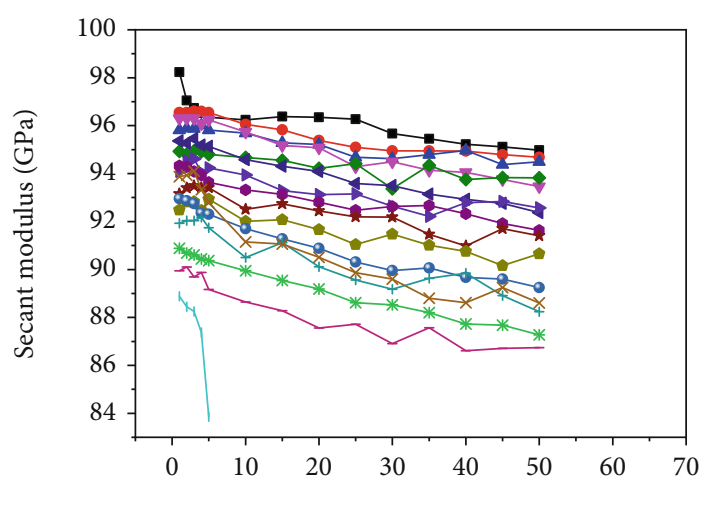

Cycle number in each level

$$
\begin{array}{ll}
\rightarrow \text { Level1 } & \rightarrow \text { Level9 } \\
\rightarrow-\text { Level2 } & \rightarrow-\text { Level10 } \\
\rightarrow \text { Level3 } & \rightarrow-\text { Level11 } \\
\rightarrow \text { Level4 } & \rightarrow \text { Level12 } \\
\rightarrow-\text { Level5 } & \rightarrow \text { Level13 } \\
\rightarrow \text { Level6 } & \rightarrow-\text { Level14 } \\
\rightarrow-\text { Level7 } & - \text { Level15 } \\
\rightarrow-\text { Level8 } & \rightarrow \text { Level16 }
\end{array}
$$

(a)

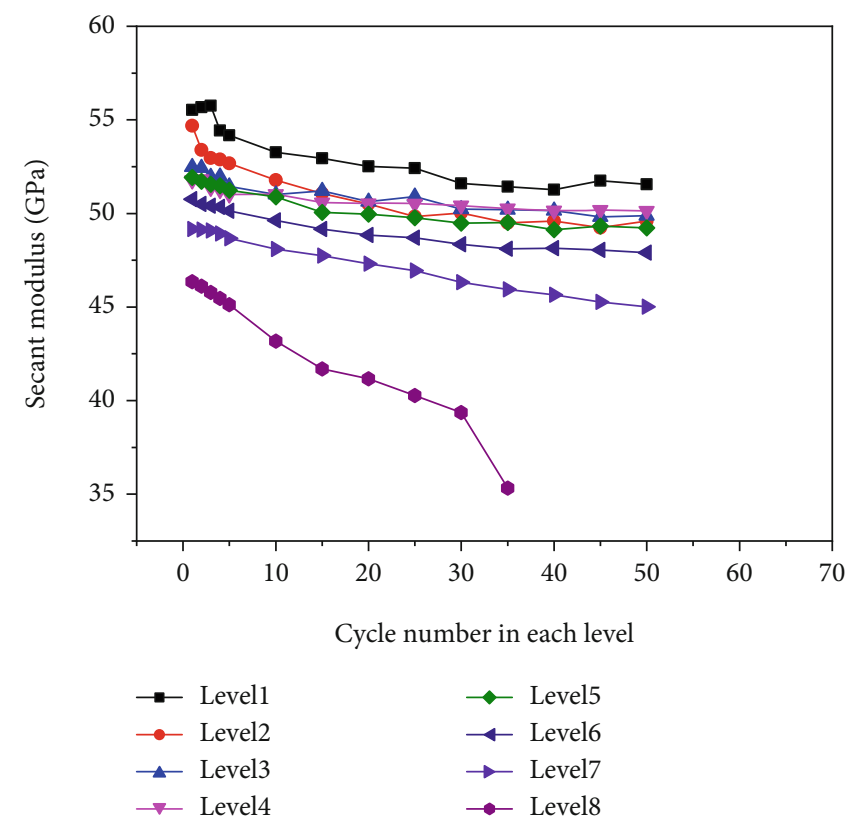

(c)

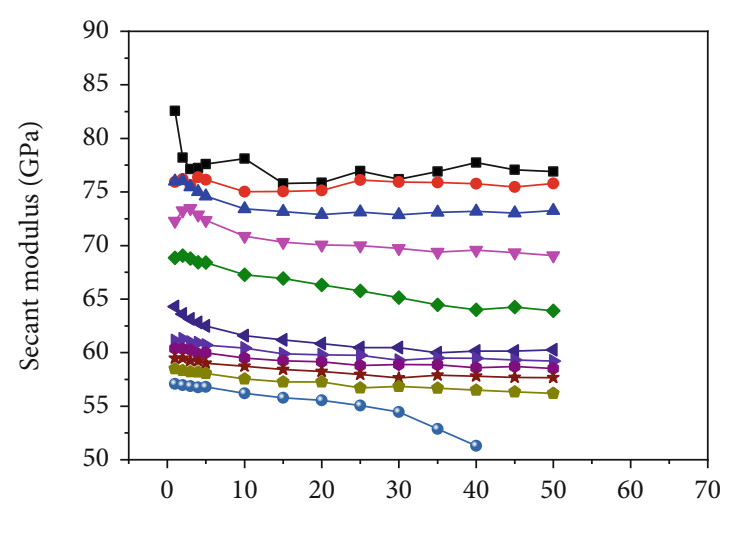

Cycle number in each level

$$
\begin{array}{ll}
\rightarrow \text { Level1 } & \rightarrow \text { Level7 } \\
\rightarrow-\text { Level2 } & \rightarrow \text { Level8 } \\
\rightarrow \text { Level3 } & \rightarrow \text { Level9 } \\
\rightarrow \text { Level4 } & \rightarrow-\text { Level10 } \\
\rightarrow-\text { Level5 } & \rightarrow \text { Level11 }
\end{array}
$$$$
\longleftarrow \text { Level6 }
$$

(b)

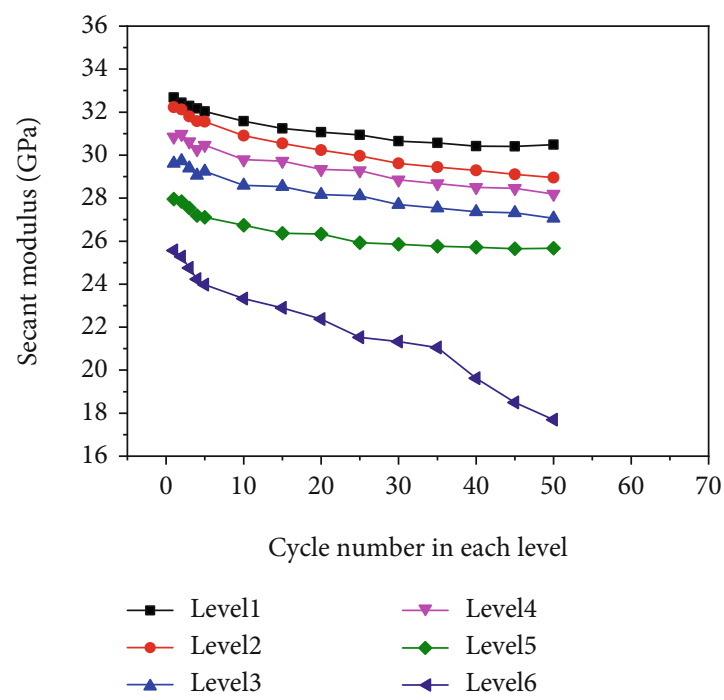

(d)

FIGURE 3: Evolution of secant modulus with cyclic number at various cyclic levels $((\mathrm{a}-\mathrm{d})$ the initial natural fracture volume ratio is $0.68 \%$, $1.03 \%, 1.53 \%$, and $2.27 \%$, respectively).

natural fracture with quartz vein $(\mathrm{CF})$, and part of the input energy is consumed to produce cracks. Although the fillingmode naturals are filled with pyrite, the macroscopic stressstrain curves display plastic deformation of marble samples. Plastic deformation resulted from irreversible deformation enhancing rock accumulative damage. For rock containing preexisting natural fracture, the damage can be attributed to the closure and sliding of natural fractures, the compaction of rock matrix, and the formation of new cracks. It is widely accepted that rock damage can be attributed to the energy dissipation during the whole deformation process. At this time, the elastic energy curve does not coincide with the total energy curve. It should be noted that as the number of cycles increases, the macroscopic stress-strain curves display plastic deformation of marble samples. Plastic deformation resulted from irreversible deformation enhancing rock accumulative damage. For rock containing preexisting natural fracture, the damage can be attributed to the closure and sliding of 


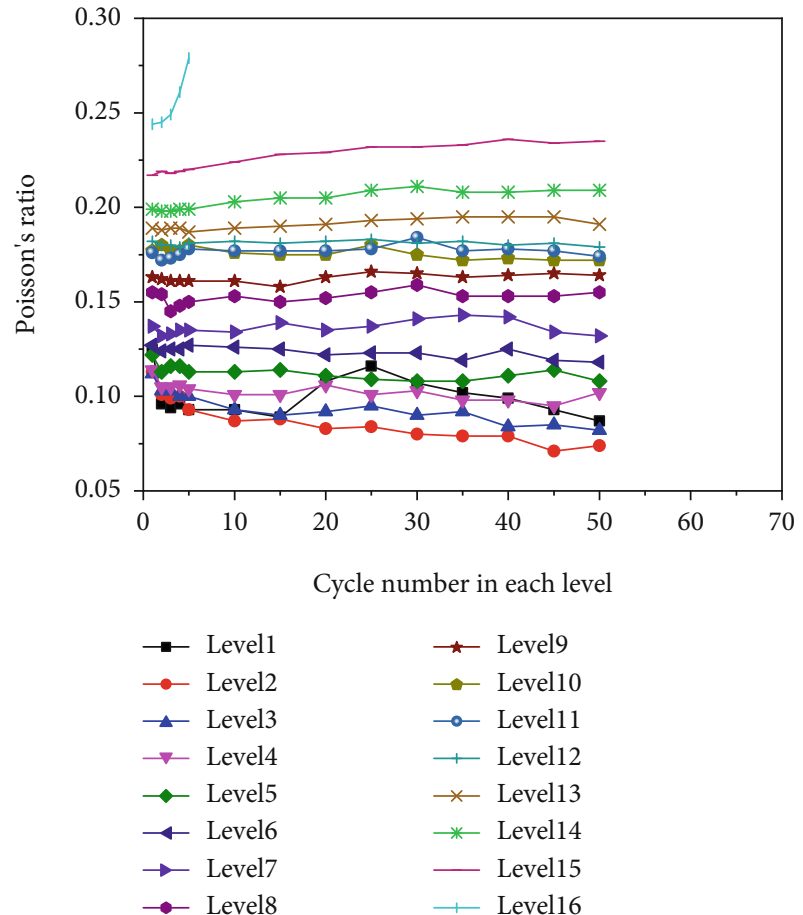

(a)

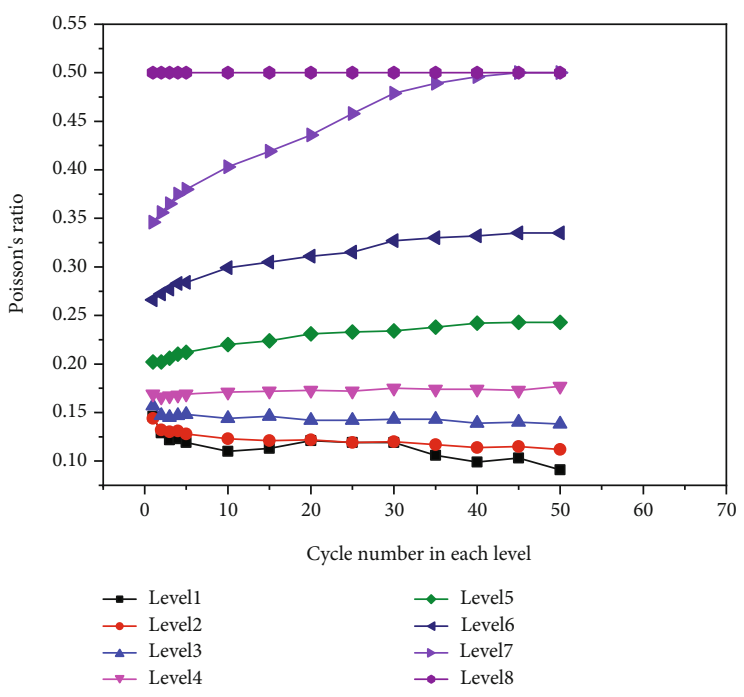

(c)

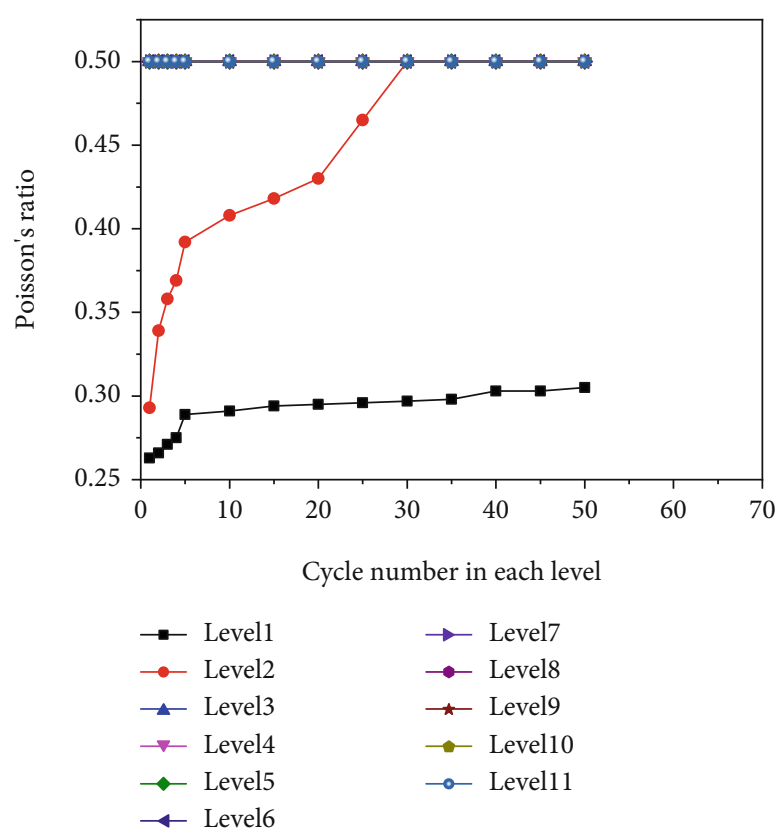

(b)

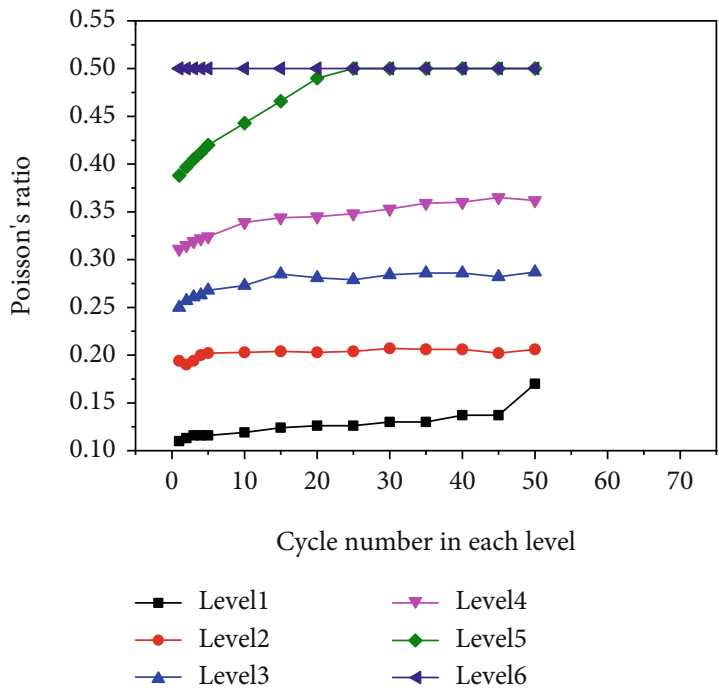

(d)

FIgURE 4: Evolution of Poisson's ratio with cyclic number at various cyclic levels $((\mathrm{a}-\mathrm{d})$ the initial natural fracture volume ratio is $0.68 \%$, $1.03 \%, 1.53 \%$, and $2.27 \%$, respectively.).

natural fractures, the compaction of rock matrix and the formation of new cracks. It is widely accepted that rock damage can be attributed to the energy dissipation during the whole deformation process.

In order to investigate the influence of natural fracture on energy evolution characteristics, Figure 6 presents the relationship between $U_{e}, U_{d}$, and cycle number. For the elastic energy, $U_{e}$, it is shown in Figure 6(a) that $U_{e}$ decreases with the increase of natural fracture volume. For a sample that has relatively small natural fracture, the input energy transferred to elastic energy occupies a high proportion; however, if the natural fracture volume is high, the deformation of natural fractures consumes a certain proportion of the input energy. In Figure 6(b), it can be seen that the overall proportion of the dissipated energy decreases with increasing natural fracture volume. This indicates that the required energy during fracture closure and stimulation is smaller than the formation of new cracks. Although the natural fracture volume is 

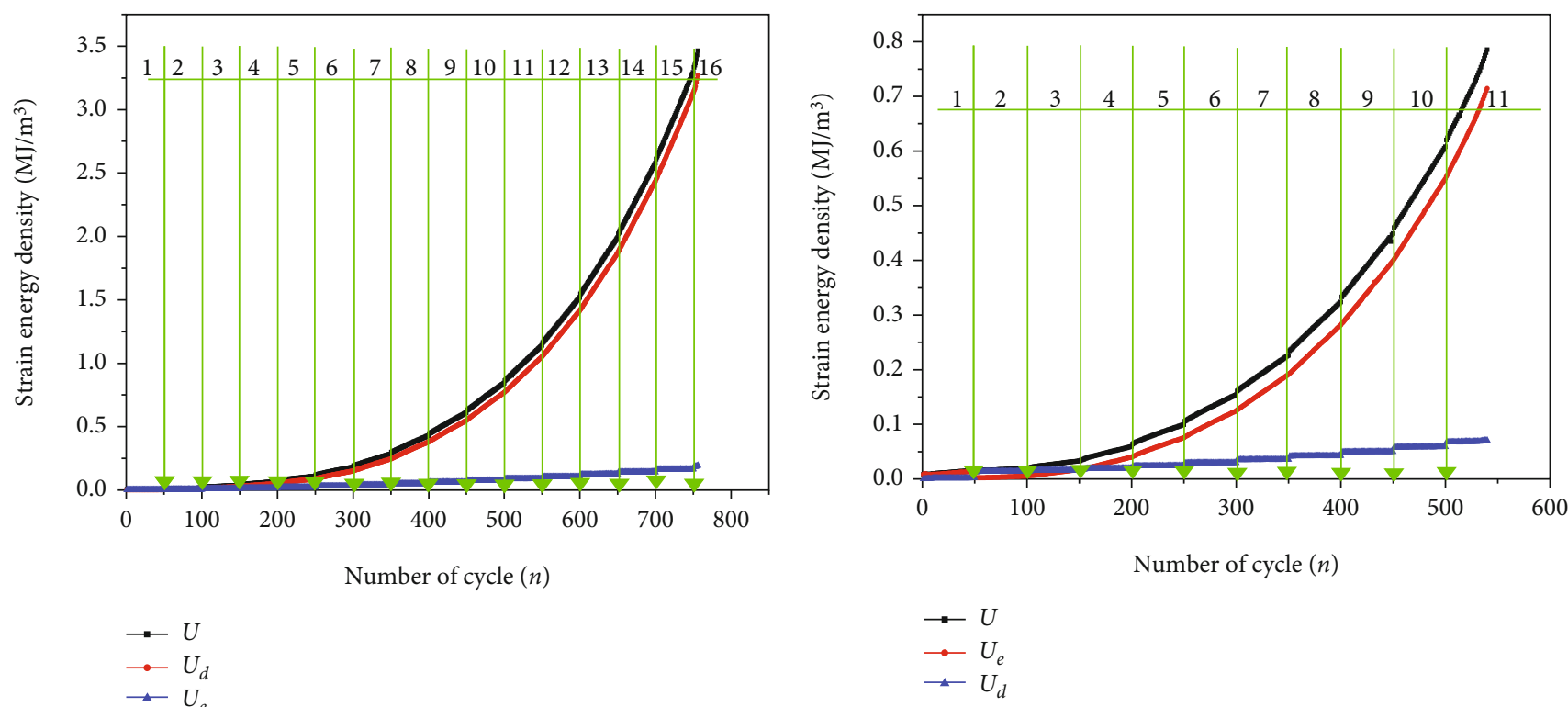

(a)

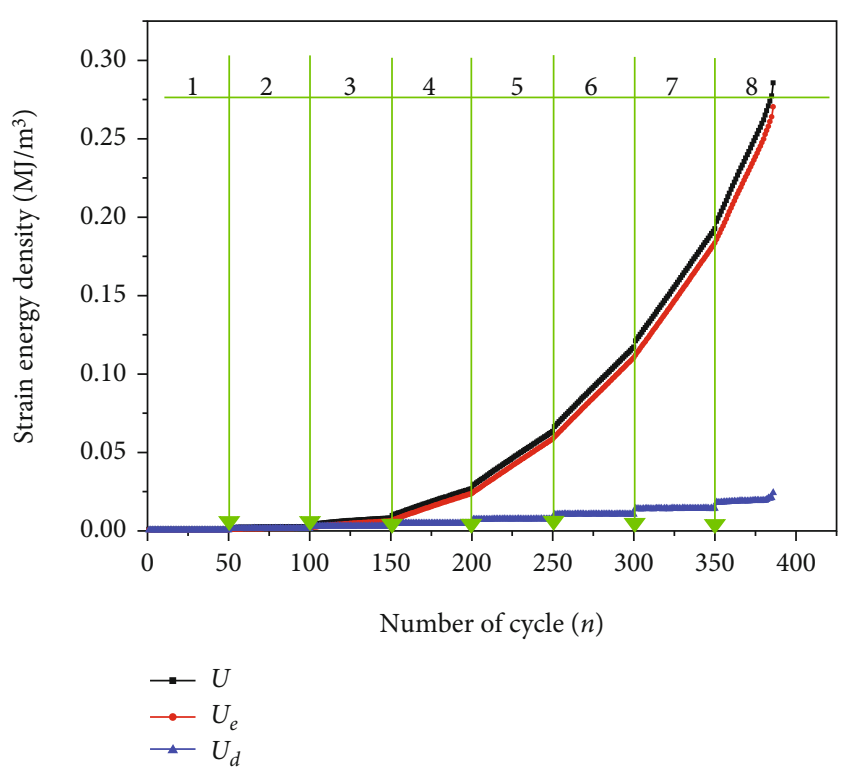

(c)

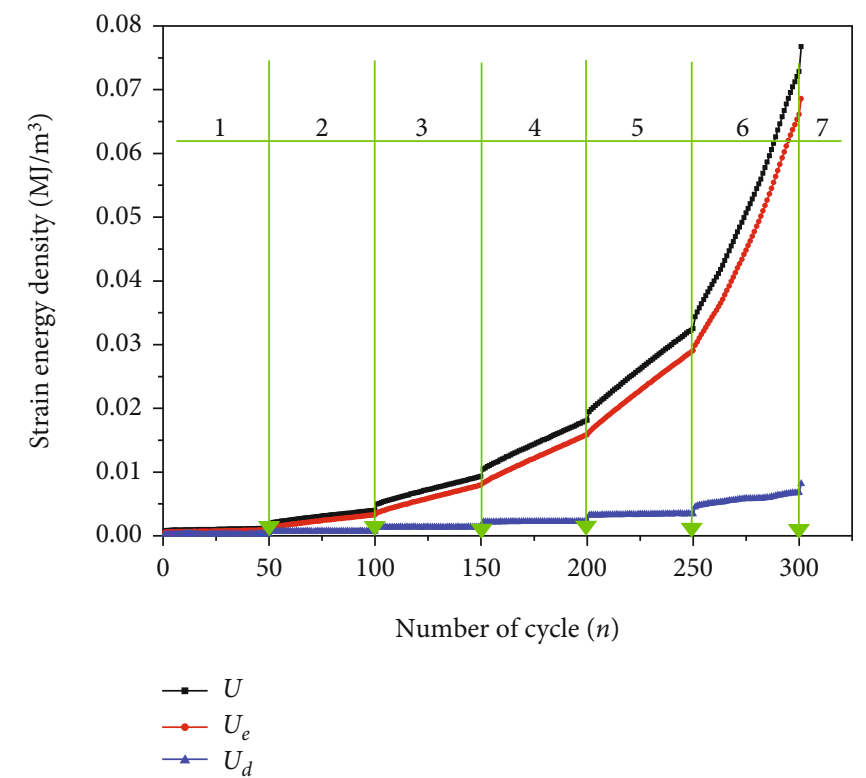

(d)

FIGURE 5: Energy evolution during rock deformation ((a-d) the initial natural fracture volume ratio is $0.68 \%, 1.03 \%, 1.53 \%$, and $2.27 \%$, respectively).

relatively high for NFM3 (i.e., 2.27\%), the dissipated energy is not so large than the other cases. This result indicates that it does not need much energy to stimulate the natural fractures; formation of new cracks needs much more energy. From Figures 6(c)-6(d), it shows that an obvious relationship exists between the $U_{e}, U_{d}$, and the total fracture volume $\left(R_{v}\right)$. There is no correlation among the $R_{\mathrm{VO}}, R_{\mathrm{VC}}$, and $R_{\mathrm{CP}}$ and $U_{e}$ and $U_{d}$. It is speculated that all the natural fractures (i.e., opening-mode natural fracture and sealed with calcite (OF), closing-mode natural fracture with quartz vein $(\mathrm{CF})$, and filling-mode natural fracture with pyrite bands (FF)) can influence the energy conversion. Although the filling-mode naturals are filled with pyrite and they are the least sensitive to freeze-thaw treatment, their deformation during cyclic loads also consumes energy.

3.4. Damage Evolution Modeling. As stated above, damage accumulation is directly related to energy dissipation during rock deformation. Energy is an effective index to evaluate rock damage evolution; the dissipated energy is used to drive damage and crack propagation. In this work, the dissipated energy is used to describe the damage evolution. Figure 7 plots the relationship between the dissipated energy $U_{d}$ and the cycle number. There is no correlation among the $R_{\mathrm{VO}}$, $R_{\mathrm{VC}}$, and $R_{\mathrm{CP}}$ and $U_{e}$ and $U_{d}$. It is speculated that all the natural fractures (i.e., opening-mode natural fracture and 


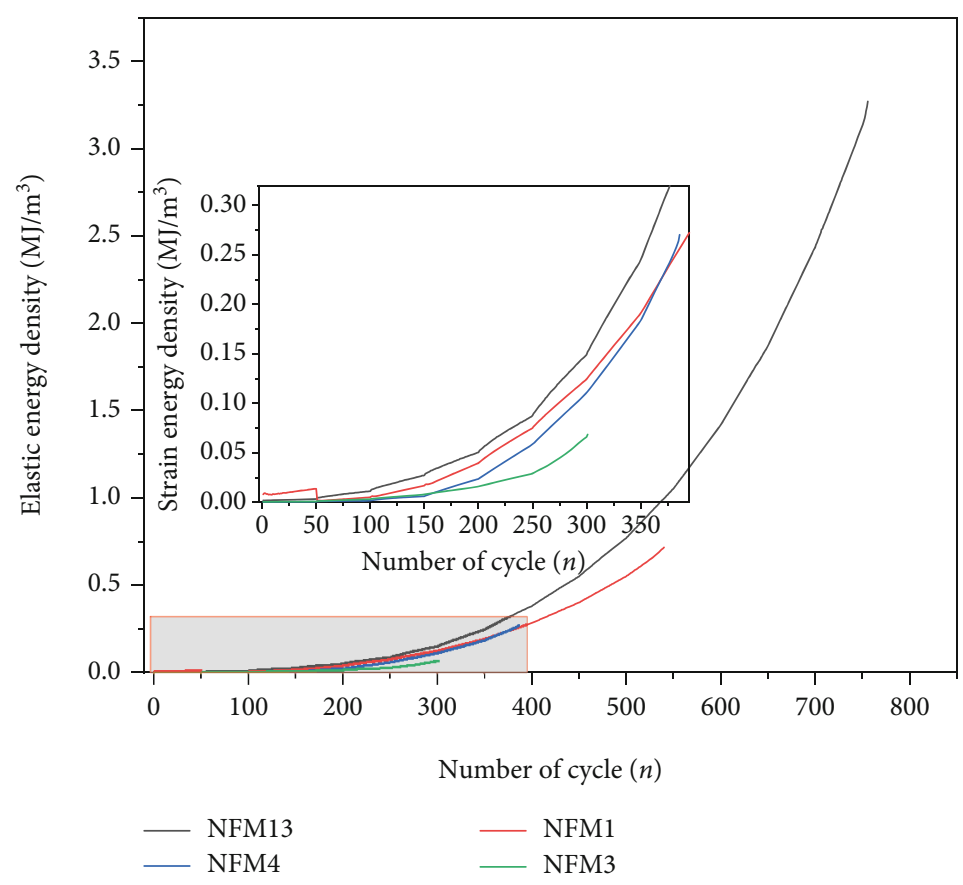

(a)

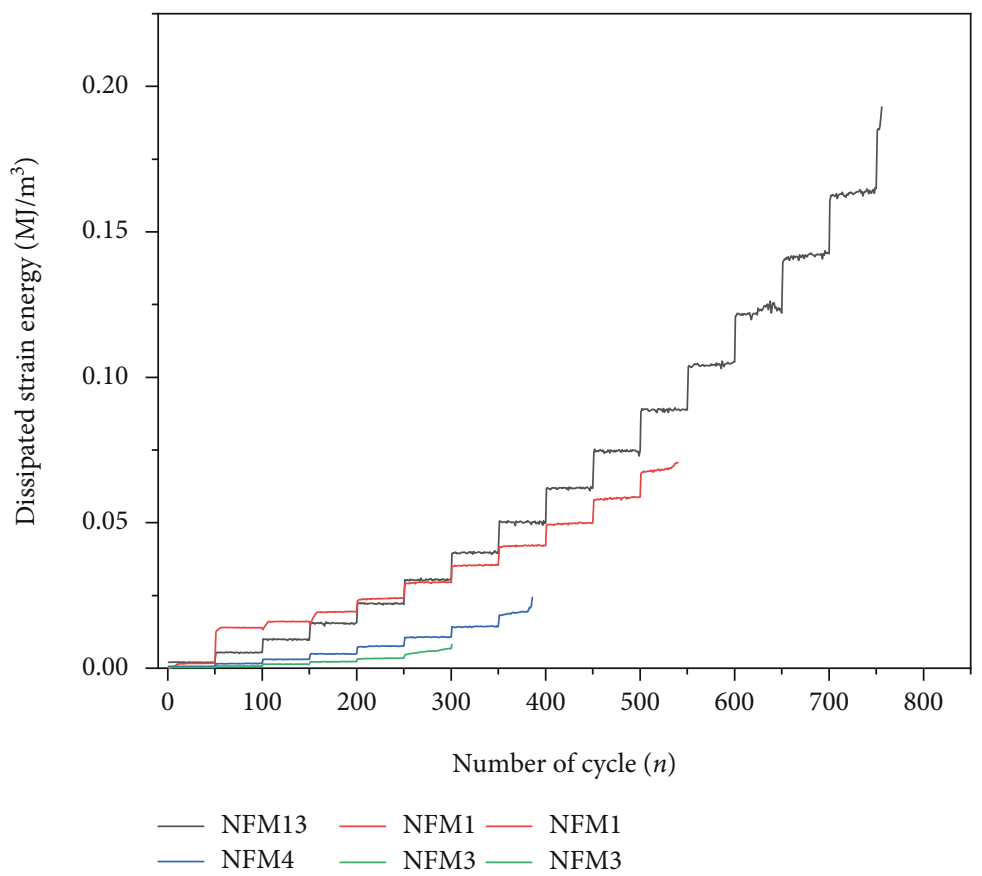

(b)

FIgURE 6: Continued. 


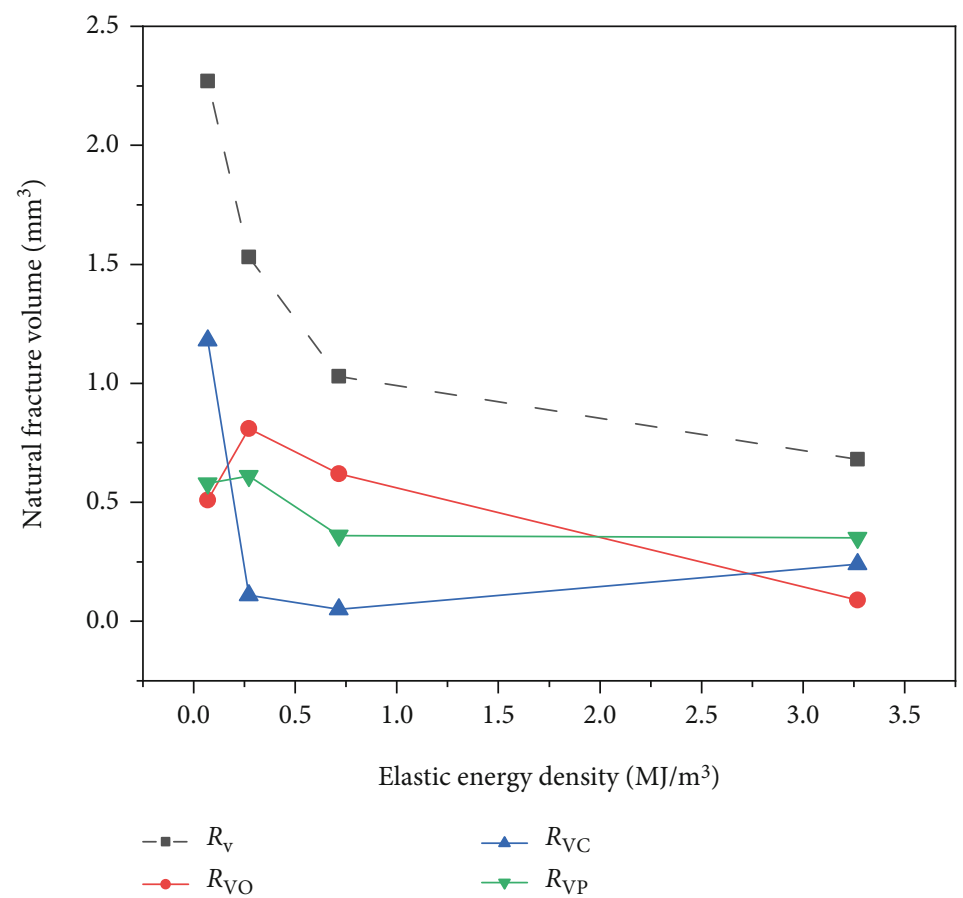

(c)

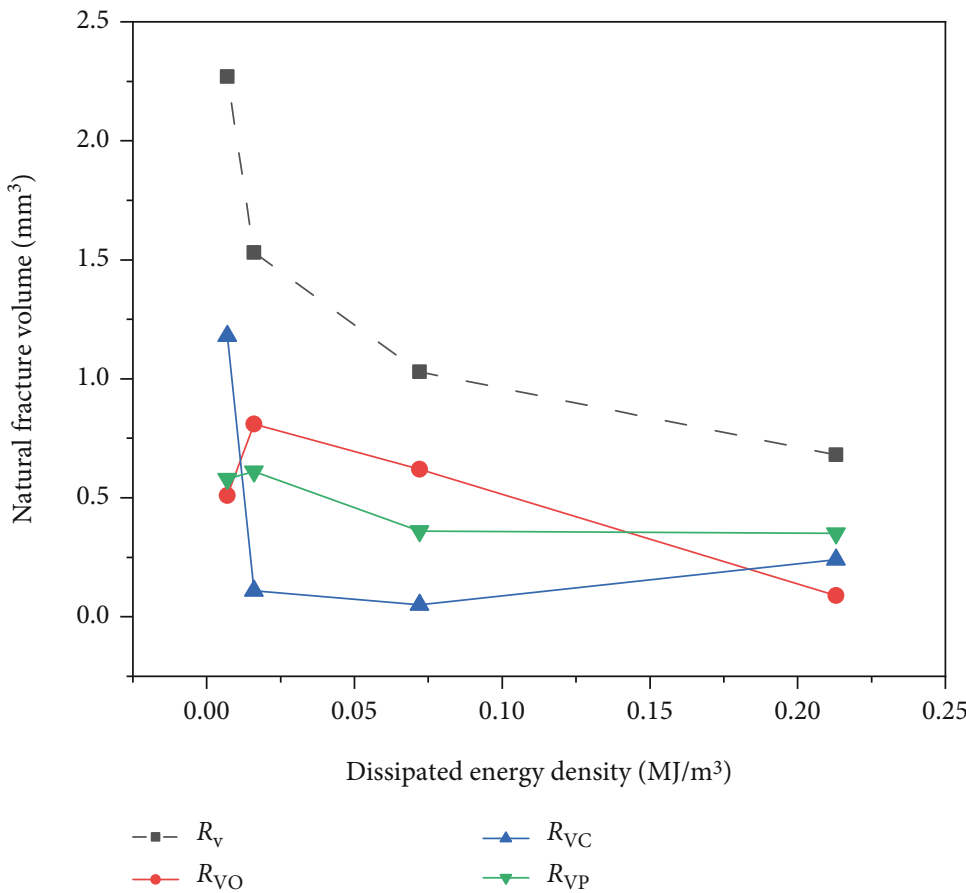

(d)

FIGURE 6: Evolution of elastic energy and dissipated energy for naturally fractured marble samples ( $(a, b)$ comparison of the elastic energy and dissipated energy with cycle number; $(c, d)$ plots of natural fracture volume against the elastic and dissipated energy).

sealed with calcite $(\mathrm{OF})$ and closing-mode natural fracture with quartz vein $(\mathrm{CF})$ ) evaluate rock damage evolution; the dissipated energy is used to drive damage and crack propagation. In this work, the dissipated energy is used too. Although the filling-mode naturals are filled with pyrite and they are the least sensitive to freeze-thaw treatment, their deformation during cyclic loads also consumes energy. The dissipated energy is $0.197,0.078,0.016$, and $0.0084 \mathrm{MJ} / \mathrm{m}^{3}$ for typical rock samples at the final cycle.

\section{Discussions}

Plenty of studies have been reported about the energy evolution characteristics of rock [18-25]. It has been widely proved 


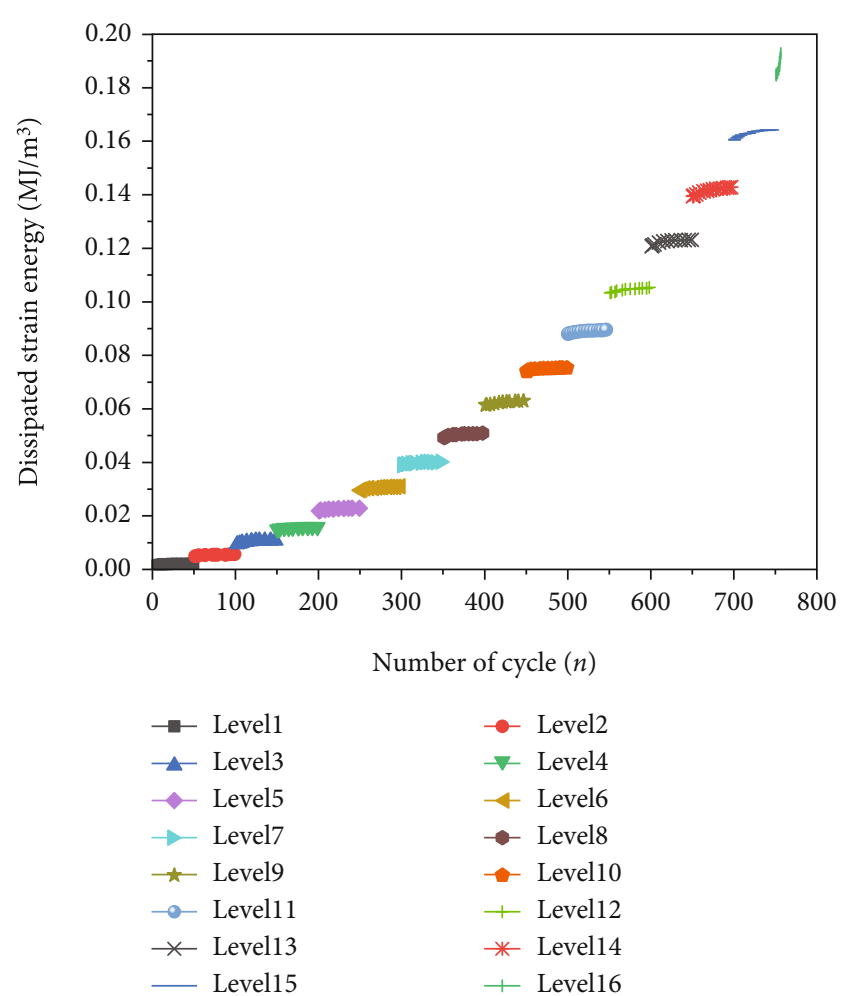

(a)

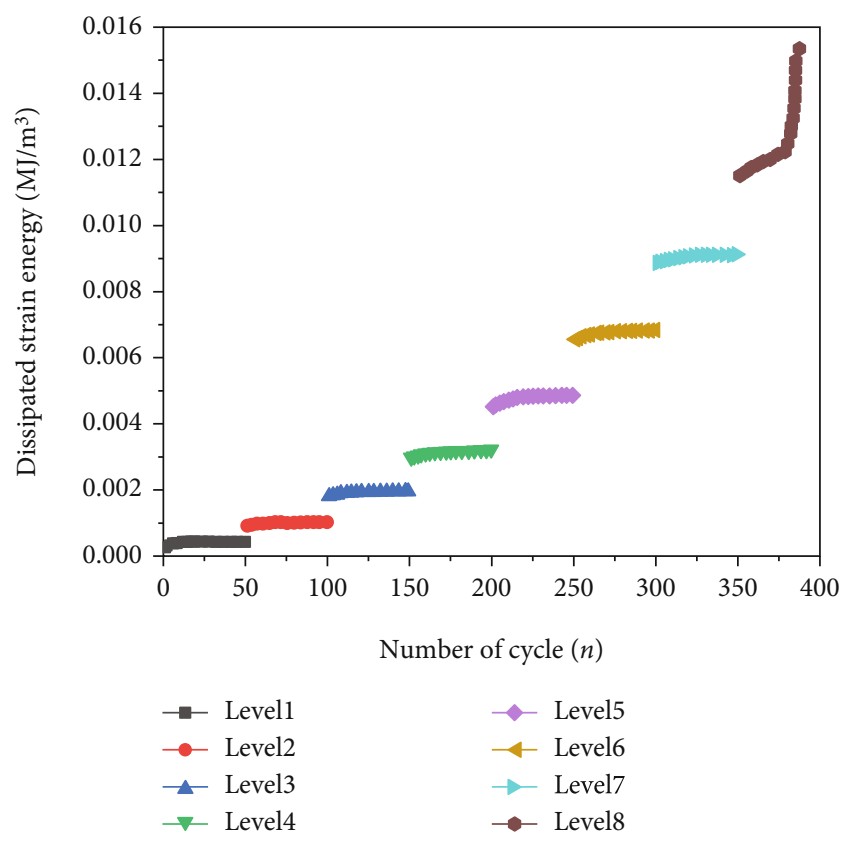

(c)

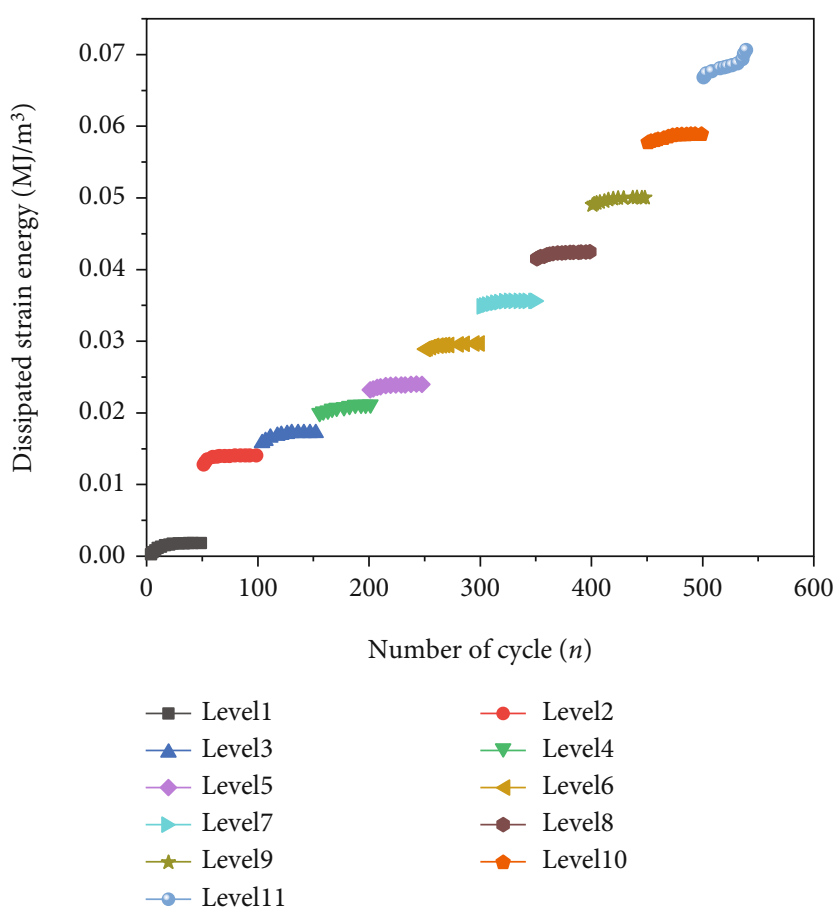

(b)

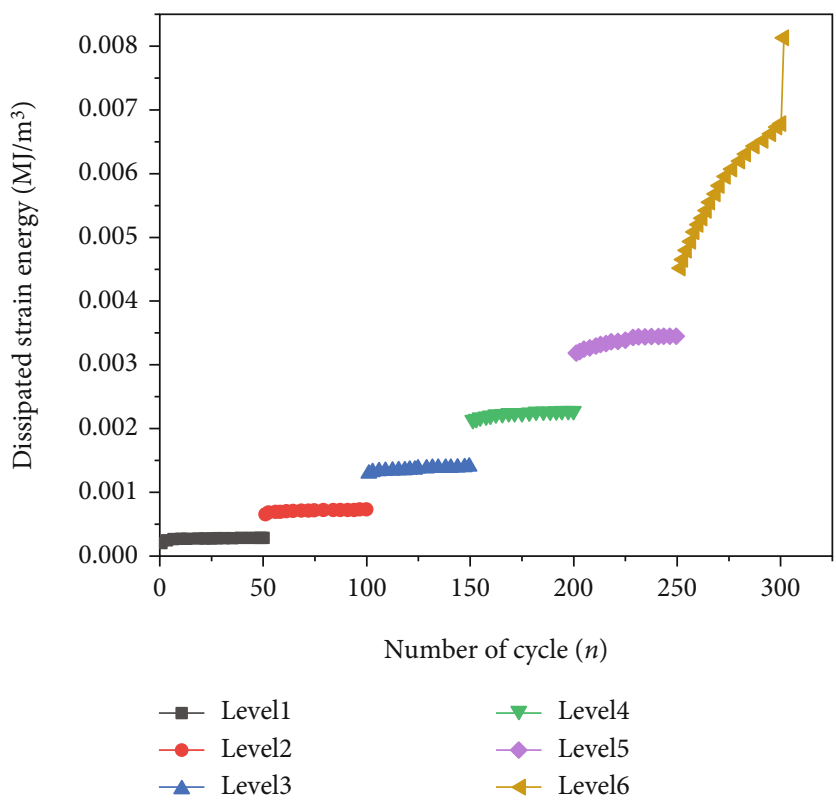

(d)

Figure 7: Relationship between the dissipated energy and cycle number ( $a-d)$ Marble samples with different total natural fracture volumes of $0.68 \%, 1.03 \%, 1.53 \%$, and $2.27 \%$, respectively).

that damage and fracturing of rock is energy-driven; energy conversion is the essential response of rock during deformation. The previous studies are focused on energy evolution for intact ore preflaw rocks [18-21]; investigation on the energy dissipation and release for naturally fractured rock is not common. This work reveals the influence of different kinds of natural fracture on the energy evolution, and multilevel cyclic loading testing was carried out to mimic stress disturbance for rock. For rock under various static loading conditions, energy conversion for rock during uniaxial compression, triaxial compression, and Brazilian testing have been widely studied. In this work, for rock under multistage 
cyclic loads, under various static loading conditions, energy conversion for rock during uniaxial compression, triaxial compression, and Brazilian testing have been widely studied. What is different is that dissipated energy increases first slowly and then become faster. At the stress-increasing moment, rock damage is much more severe than the cyclic loading process. According to the two-stage damage accumulation pattern, the pervious inverted "S"-shaped damage evolution model is not suitable for rock under multistage cyclic loads. It is widely accepted that inverted "S" shape models are employed to describe the damage evolution process of marble. For example, Zhang et al. [34] defined a new general damage model to observe the degradation of composite materials. It was shown that the model they proposed could more accurately simulate the rapid damage growth during the early fatigue period and towards the end of the fatigue life. The applicability of their model to rock fatigue damage evolution has also been proved to be applicable to rocks under constant amplitude fatigue loading conditions [6]. To describe the two-stage damage evolution characteristics, a model distinguished from the conventional damage model is proposed from energy dissipation. Generally, some mechanical parameters, such as strain, stress, and elastic modulus are used to establish a fatigue damage constitutive equation [35-38]. The drawback of this method is that the stress and strain information is relatively simple and not well reflects the internal damage of rock. However, the energy contains compressive information about rock fracturing, such as stress, strain, and elastic modulus; in addition, obtaining of energy is nondestructive and there is no need to terminate a test. It is found that the fatigue damage model established by the dissipated energy can well fit the experimental data and the correlation coefficient is high enough.

\section{Conclusions}

In this work, energy conversion characteristics of natural fractured rock were investigated. Typical marble samples containing natural fractures are used in this work to carry out multilevel cyclic compressive loading testing. The influence of the initial natural fracture volume on the stress-strain responses, and also, the energy dissipation were discussed in detail. Based on the studies above, the main conclusions are summarized as below:

(1) The natural fractures in marble impact energy dissipation and release pattern. The dissipated energy increases with the increase of total natural fracture volume. The dissipated energy is correlated to the total natural fracture volume, and it is shown that all the natural fractures no matter how their physical state influences fatigue damage accumulation

(2) Rock damage evolution is described using the dissipated energy, and the increasing rate of dissipated energy grows faster with increasing cyclic levels. Stimulation of natural fractures consumes smaller proportion of the input energy compared to the newly formed cracks. The dissipated energy at the stress-increasing moment increases sharply than the cyclic loading process

(3) Typical marble samples containing natural fractures are used in this work; a damage model was established according to change of energy to describe the damage accumulation during rock deformation. The reliability of the model was validated by comparing the tested and predicted results

\section{Data Availability}

The experimental data used to support the findings of this study are included within the article.

\section{Conflicts of Interest}

The authors declare no conflict of interest.

\section{Acknowledgments}

This research was funded by the Beijing Natural Science Foundation (8202033), Tiandi science and technology innovation and venture capital special (2018-TD-QN041), Beijing science and technology project (Z181100005118012), and Fundamental Research Funds for the Central Universities (FRF-TP-20-004A2).

\section{References}

[1] Y. Wang, C. H. Li, H. Liu, and J. Q. Han, "Fracture failure analysis of freeze-thawed granite containing natural fracture under uniaxial multi-level cyclic loads," Theoretical and Applied Fracture Mechanics, vol. 110, p. 102782, 2020.

[2] Z. G. Tao, C. Zhu, M. C. He, and M. Karakus, "A physical modeling-based study on the control mechanisms of Negative Poisson's ratio anchor cable on the stratified toppling deformation of anti- inclined slopes," International Journal of Rock Mechanics and Mining Sciences, vol. 138, p. 104632, 2021.

[3] Y. Wang, C. H. Li, and J. Q. Han, "On the effect of stress amplitude on fracture and energy evolution of pre- flawed granite under uniaxial increasing-amplitude fatigue loads," Engineering Fracture Mechanics, vol. 240, p. 107366, 2020.

[4] Z. Y. Song, Y. Wang, H. Konietzky, and X. Cai, "Mechanical behavior of marble exposed to freeze-thaw-fatigue loading," International Journal of Rock Mechanics and Mining Sciences, vol. 138, p. 104648, 2021.

[5] Y. Hashash, J. Hook, B. Schmidt, and J. I-Chiang Yao, "Seismic design and analysis of underground structures," Tunnelling and Underground Space Technology, vol. 16, no. 4, pp. 247293, 2001.

[6] Y. Wang, S. H. Gao, C. H. Li, and J. Q. Han, "Energy dissipation and damage evolution for dynamic fracture of marble subjected to freeze-thaw and multiple level compressive fatigue loading," International Journal of Fatigue, vol. 142, article 105927, 2021.

[7] Y. Wang, W. K. Feng, H. J. Wang, C. H. Li, and Z. Q. Hou, "Rock bridge fracturing characteristics in granite induced by freeze-thaw and uniaxial deformation revealed by AE monitoring and post-test CT scanning," Cold Regions Science and Technology, vol. 177, p. 103115, 2020. 
[8] Y. Wang, D. Liu, J. Han, C. Li, and H. Liu, "Effect of fatigue loading-confining stress unloading rate on marble mechanical behaviors: an insight into fracture evolution analyses," Journal of Rock Mechanics and Geotechnical Engineering, vol. 12, no. 6, pp. 1249-1262, 2020.

[9] Y. Wang, W. K. Feng, R. L. Hu, and C. H. Li, "Fracture evolution and energy characteristics during marble failure under triaxial fatigue cyclic and confining pressure unloading (FCCPU) conditions," Rock Mechanics and Rock Engineering, vol. 54, no. 2, pp. 799-818, 2021.

[10] M. N. Bagde and V. Petroš, "Fatigue properties of intact sandstone samples subjected to dynamic uniaxial cyclical loading," International Journal of Rock Mechanics and Mining Sciences, vol. 42, no. 2, pp. 237-250, 2005.

[11] A. Momeni, M. Karakus, G. R. Khanlari, and M. Heidari, "Effects of cyclic loading on the mechanical properties of a granite," International Journal of Rock Mechanics and Mining Sciences, vol. 77, pp. 89-96, 2015.

[12] Y. Liu, F. Dai, P. Fan, N. Xu, and L. Dong, "Experimental investigation of the influence of joint geometric configurations on the mechanical properties of intermittent jointed rock models under cyclic uniaxial compression," Rock Mechanics and Rock Engineering, vol. 50, no. 6, pp. 1453-1471, 2017.

[13] B. Li, R. Bao, Y. Wang, R. Liu, and C. Zhao, "Permeability evolution of two-dimensional fracture networks during shear under constant normal stiffness boundary conditions," Rock Mechanics and Rock Engineering, vol. 54, no. 1, pp. 409-428, 2021.

[14] B. Cerfontaine and F. Collin, "Cyclic and fatigue behaviour of rock materials: review, interpretation and research perspectives," Rock Mechanics and Rock Engineering, vol. 51, no. 2, pp. 391-414, 2018.

[15] Y. Wang, H. J. Meng, and D. Y. Long, "Experimental investigation of fatigue crack propagation in interbedded marble under multilevel cyclic uniaxial compressive loads," Fatigue \& Fracture of Engineering Materials \& Structures, vol. 44, no. 4, pp. 933-951, 2020.

[16] D. Shiozawa, K. Inaba, A. Akai, and T. Sakagami, "Experimental study of relationship between energy dissipation and fatigue damage from observation of slip band by atomic force microscope," Advances in Materials Research, vol. 891-892, pp. 606-611, 2014.

[17] H. P. Xie, L. Y. Li, Y. Ju, R. D. Peng, and Y. M. Yang, "Energy analysis for damage and catastrophic failure of rocks," Science China Technological Sciences, vol. 54, no. S1, pp. 199-209, 2011.

[18] T. Wang, H. Zhang, R. P. Gamage, W. Zhao, J. Ge, and Y. Li, "The evaluation criteria for rock brittleness based on doublebody analysis under uniaxial compression," Geomechanics and Geophysics for Geo-Energy and Geo-Resources, vol. 6, no. 3, pp. 1-19, 2020.

[19] Y. Wang, Y. F. Yi, C. H. Li, and J. Q. Han, "Anisotropic fracture and energy characteristics of a Tibet marble exposed to multi-level constant-amplitude (MLCA) cyclic loads: a labscale testing," Engineering fracture mechanics., vol. 244, article 107550, 2021.

[20] P. Cornetti, N. Pugno, A. Carpinteri, and D. Taylor, "Finite fracture mechanics: a coupled stress and energy failure criterion," Engineering Fracture Mechanics, vol. 73, no. 14, pp. 2021-2033, 2006.

[21] L. Zhang, Y. Cong, F. Meng, Z. Wang, P. Zhang, and S. Gao, "Energy evolution analysis and failure criteria for rock under different stress paths," Acta Geotechnica, vol. 16, no. 2, pp. 569-580, 2020.

[22] X. Cai, Z. L. Zhou, L. Tan, H. Zang, and Z. Song, "Fracture behavior and damage mechanisms of sandstone subjected to wetting- drying cycles," Engineering Fracture Mechanics, vol. 234, article 107109, 2020.

[23] C. Zhu, M. C. He, M. Karakus, X. H. Zhang, and Z. G. Tao, "Numerical simulations of the failure process of anaclinal slope physical model and control mechanism of negative Poisson's ratio cable," Bulletin of Engineering Geology and the Environment, vol. 80, no. 4, pp. 3365-3380, 2021.

[24] Y. Zhou, Q. Sheng, N. Li, and X. Fu, “The influence of strain rate on the energy characteristics and damage evolution of rock materials under dynamic uniaxial compression," Rock Mechanics and Rock Engineering, vol. 53, no. 8, pp. 38233834, 2020.

[25] A. Z. Hua and M. Q. You, "Rock failure due to energy release during unloading and application to underground rock burst control," Tunnelling and Underground Space Technology, vol. 16, no. 3, pp. 241-246, 2001.

[26] Y. Wang, B. Zhang, S. H. Gao, and C. H. Li, "Investigation on the effect of freeze-thaw on fracture mode classification in marble subjected to multi-level cyclic loads," Theoretical and Applied Fracture Mechanics, vol. 111, p. 102847, 2021.

[27] T. Li, X. Pei, J. Guo, M. Meng, and R. Huang, "An energybased fatigue damage model for sandstone subjected to cyclic loading," Rock Mechanics and Rock Engineering, vol. 53, no. 11, pp. 5069-5079, 2020.

[28] Y. Wang, W. K. Feng, and C. H. Li, "On anisotropic fracture and energy evolution of marble subjected to triaxial fatigue cyclic-confining pressure unloading conditions," International Journal of Fatigue, vol. 134, p. 105524, 2020.

[29] S. Pu, Z. Zhu, L. Song, W. Song, and Y. Peng, "Fractional-order visco-elastoplastic constitutive model for rock under cyclic loading," Arabian Journal of Geosciences, vol. 13, no. 9, pp. 1-11, 2020.

[30] Y. J. Yang, H. Q. Duan, L. Y. Xing, and L. Deng, "Fatigue characteristics of coal specimens under cyclic uniaxial loading," Geotechnical Testing Journal, vol. 42, no. 2, pp. 20170263 20170346, 2019.

[31] Y. Liu, F. Dai, L. Dong, N. Xu, and P. Feng, "Experimental investigation on the fatigue mechanical properties of intermittently jointed rock models under cyclic uniaxial compression with different loading parameters," Rock Mechanics and Rock Engineering, vol. 51, no. 1, pp. 47-68, 2018.

[32] M. N. Bagde and V. Petroš, "Fatigue and dynamic energy behaviour of rock subjected to cyclical loading," International Journal of Rock Mechanics and Mining Sciences, vol. 46, no. 1, pp. 200-209, 2009.

[33] R. Solecki and R. J. Conant, Advanced Mechanics of Materials, Oxford University Press, London, 2003.

[34] M. Zhang, L. Dou, H. Konietzky, Z. Song, and S. Huang, "Cyclic fatigue characteristics of strong burst-prone coal: experimental insights from energy dissipation, hysteresis and micro-seismicity," International Journal of Fatigue, vol. 133, p. 105429, 2020.

[35] A. Li, F. Dai, Y. Liu, H. B. Du, and R. C. Jiang, "Dynamic stability evaluation of underground cavern sidewalls against flexural toppling considering excavation-induced damage," Tunnelling and Underground Space Technology, vol. 112, p. 103903, 2021. 
[36] Q. X. Meng, W. Y. Xu, H. L. Wang, X. Y. Zhuang, W. C. Xie, and T. Rabczuk, "DigiSim - an open source software package for heterogeneous material modeling based on digital image processing," Advances in Engineering Software, vol. 148, p. 102836, 2020.

[37] T. Zhigang, Z. Chun, H. Manchao, and L. Kuiming, "Research on the safe mining depth of anti-dip bedding slope in Changshanhao Mine," Geomechanics and Geophysics for Geo-Energy and Geo-Resources, vol. 6, no. 2, pp. 1-20, 2020.

[38] Q. Wang, H. K. Gao, B. Jiang, S. C. Li, M. C. He, and Q. Qin, "In-situ test and bolt-grouting design evaluation method of underground engineering based on digital drilling," International Journal of Rock Mechanics and Mining Sciences., vol. 138, p. 104575, 2021.

[39] H. Mao and S. Mahadevan, "Fatigue damage modelling of composite materials," Composite Structures, vol. 58, no. 4, pp. 405-410, 2002. 